\title{
THE GENERATIVE DESIGN AND ANALYSIS OF A FORMULA ONE RACE CAR CHASSIS
}

\author{
Dr. V. BALAMBICA ${ }^{1}$, S. VEERENDRANATH ${ }^{2}$, P. GNANESWAR ${ }^{2}$, \\ P. PAVAN KALIAN ${ }^{2} \&$ S. LOKESWARA MANIKANTA ${ }^{2}$ \\ ${ }^{\text {I} A s s o c i a t e ~ P r o f e s s o r, ~ D e p a r t m e n t ~ o f ~ M e c h a n i c a l ~ E n g i n e e r i n g, ~ B h a r a t h ~ I n s t i t u t e ~ o f ~ H i g h e r ~}$ \\ Education and Research, Selaiyur, Chennai, Tamilnadu, India \\ ${ }^{2}$ Students, Department of Mechanical Engineering, Bharath Institute of Higher \\ Education and Research, Selaiyur, Chennai, Tamilnadu, India
}

\begin{abstract}
A general Formula One (F1) Racing Car chassis requires great strength to bear the damages caused due to the crash. So, our aim is to maximize the strength of the Formula One race car chassis by using Generative design so that it can overcome the crashing damages of shear and buckling of it by referring it to space frame chassis and performing the crash analysis on the chassis. In this undergraduate Research project, a Formula One race car will be designed using the CAD software Autodesk Fusion 360. In the design of the space frame chassis, all the dimensions are based on the standards laid down by Formula SAE rules (SAE International). Crash Analysis is done using ANSYS Workbench software.
\end{abstract}

KEYWORDS: Formula One Race Car, Generative Design, Space Frame Chassis \& Crash Analysis

Received: May 13, 2019; Accepted: Jun 03, 2019; Published: Aug 14, 2019; Paper Id.: IJMPERDAUG2019140

\section{INTRODUCTION}

\section{General Study}

Many accidents of formula 1 race cars have been noticed, that are caused by crashing of the vehicle. General damages caused by crashing are structural failure and buckling of the vehicle. There have been many incidents of deaths of the F1 race car drivers caused by crashing.

\section{Chassis and its Importance}

A chassis is the framework of an artificial object, which supports the object in its construction and use. An example of a chassis is a vehicle frame, the under part of a motor vehicle, on which the body is mounted; if the running gear such as wheels and transmission, and sometimes even the driver's seat, are included, then the assembly is described as a rolling chassis. Chassis is one of the most important parts of vehicles. It has several functions. It is analogous to the skeleton of animals. Chassis holds almost all of the components of the vehicle together. At the same time, it serves a safe zone for drivers to protect them. Chassis must be strong enough to remain robust in every operational condition for its expected life and also be as light as possible to be fast. It carries the suspension system and that's why chassis must minimize body deflection as bending and torsion in any direction. This chassis stiffness affects the vehicle's dynamic behaviors like road holding and handling. 


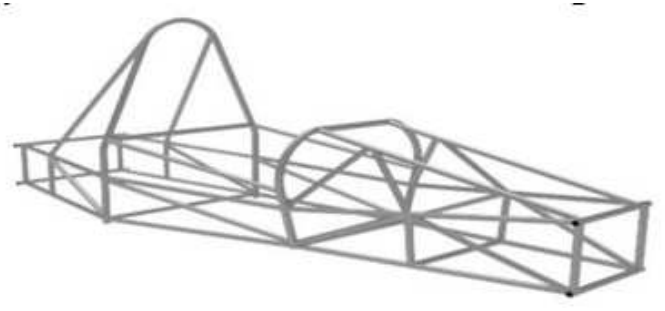

Figure 1: Isometric View of Car Chassis

\section{Outline of the Project}

Our aim is to maximize the strength of the Formula One race car chassis by using Generative design so that it can overcome the crashing damages of shear and buckling of it by referring it to space frame chassis and performing the crash analysis on the chassis. In this undergraduate Research project, a Formula One race car will be designed using the CAD software Autodesk Fusion 360. In the design of the space frame chassis, all the dimensions are based on the standards laid down by Formula SAE rules (SAE International).

By using these dimensions, a modified design of the Formula 1 race car chassis is designed by using Generative Design technology in Autodesk Fusion 360 software.

Later, static structural analysis is done using Autodesk Fusion 360 software to determine the structural strength of the chassis.

Then, Crash analysis is done on the design of the chassis using ANSYS software to determine whether the chassis can withstand the impact caused by the crash.

Thus, by these analyses and their results, we conclude that by generative design strength of the chassis has been increased considerably.

\section{LITERATURE REVIEW}

With the first appearance of automobiles at the end of the 18th century, it took almost a century, the development of combustion engine powered automobiles. Before long the first automobile race was organized in the United States in 1895 (www.eyewitnesstohistory.com, 2006). Being a strong competitive environment, automobile races have taken the lead of faster development of cars. Thus, automobile races are a good opportunity for manufacturers. Because they always have to be faster, stronger and safer. V. Balambica (et al), in her paper had discussed that in order to avoid under cutting and interference profile modification of the gear was done. The paper described about the model, meshing and the analytical techniques. Work was done to develop the tooth profile, also the root region by calculating the coordinates using C language. V. Balambica (et al), in her paper discussed that earlier the stiffness and deflection of the gear tooth was studied to find the dynamic load acting. This was done with the tooth being assumed as a short small cantilever. But in reality, an in volute profile is the shape of the spur gear tooth. Based on this reality, work was done in modeling the true profile of the gear tooth. Later, the stiffness of the tooth was carefully analysed and an improvement was made. It was proved that FEA was one such technique that could be used for predicting loads with respect to time acting on gear tooth. 


\section{DESIGN}

\section{Design Overview}

Our project is about the f1 race car, the company won't specify anywhere about details or car 3D model. All the specification about the car will maintain very confidentially by company community. so we didn't get any model or dimension. To design the model of chassis of car we required dimensions so we started searching for the dimension in journal papers

From some journal paper, we got the 2D dimension for the f1 race car, then we started designing the 2D diagram in fusion 360 software

\section{Calculation Normal Speed of Race Car is $350 \mathrm{kmph}$ Velocity $=\mathbf{8 3 . 3 3 ~} \mathrm{m} / \mathrm{s}$ to Calculate the Impact Load}

We know that impact force $=\frac{2}{d}$

\section{$1 m v 2$}

Mass $=340 \mathrm{~kg}$

$\mathrm{D}=300 \mathrm{~mm}$ or $300 * \mathrm{e}-3$

$\mathrm{F}=\frac{\frac{\frac{1}{2} * 340 * 83.33^{2}}{300 e-3}}{30}=79033$ newton

To apply the factor of safety we took the impact force as 500000 newtons

\section{MODELLING}

As we don't have a readily available model to generate the generative design, so we need to create the 3D model to go into the generative design process.

\section{D Modelling}

To proceed to $3 \mathrm{~d}$ modelling we need design the $2 \mathrm{~d}$ design. So, we did the $2 \mathrm{~d}$ design we got all dimensions as shown in fig

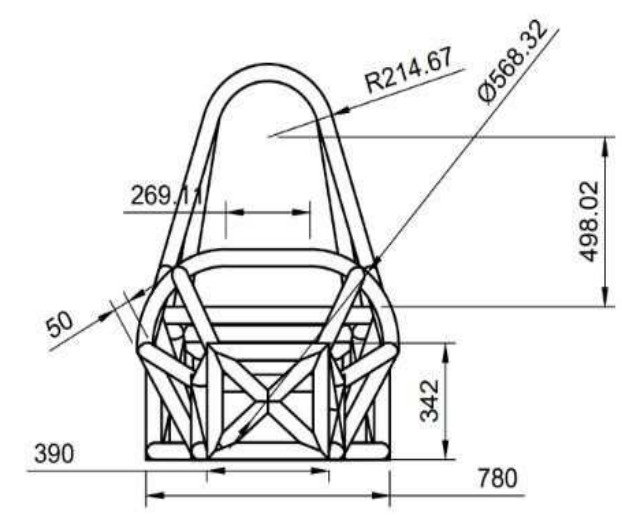

Figure 1: Front View of 2d Model Chassis 


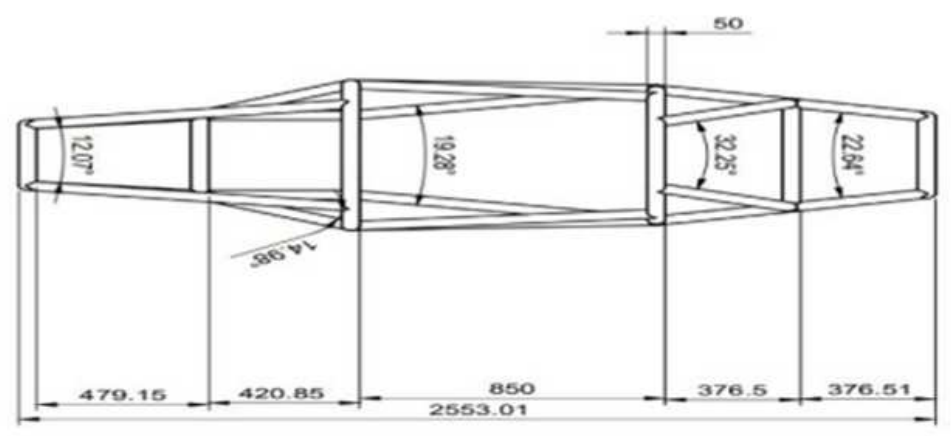

Figure 2: Top View of the Chassis -2D Model

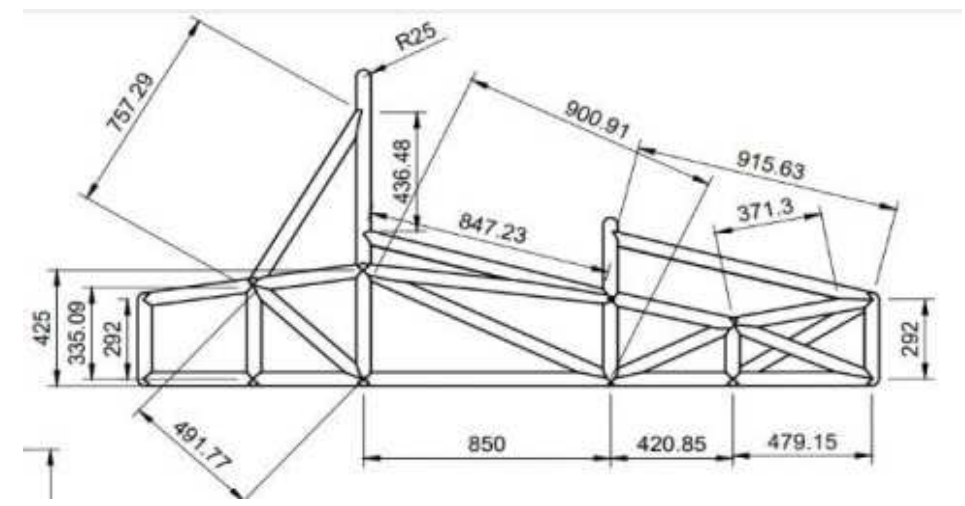

Figure 3: Side View of 2d Design Chassis (All Dimensions Are In Mm)

\section{D Modelling}

To get into modelling we decided to do that in fusion 360 software as we are comforted with that. We are done the modelling with reference of $2 \mathrm{D}$ dimension got from journal paper.

All the parameters are strictly followed from the 2D diagrams only.

\section{Generative Design}

Generative design is an iterative design process that involves a program that will generate a certain number of outputs that meet certain constraints, and a designer that will fine tune the feasible region by changing minimal and maximal values of an interval in which a variable of the program meets the set of constraints, in order to reduce or augment the number of outputs to choose from.

The generative design mimics nature's evolutionary approach to design. Designers or engineers input design goals into generative design software, along with parameters such as materials, manufacturing methods, and cost constraints. Unlike topology optimization, the software explores all the possible permutations of a solution, quickly generating design alternatives. It tests and learns from each iteration what works and what doesn't. 

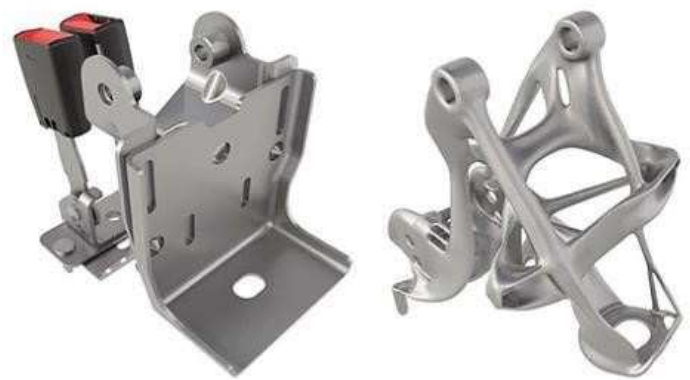

Figure 4: Samples of a Generative Design

Our aim is to increase the strength of chassis in buckling conditions of car in race. This design is not for only front impact but also side impact also. We design in such way by giving some supports to chassis. So, we went with change of shape of chassis with help of generative process. We done the generative process in fusion 360 generative design software. it will give many models which are similar with our design and according to our conditions (weight, strength, shape)

After $3 \mathrm{~d}$ modelling is completed we have to that file in step file format. Then we have to subscribe the generative software from official website after getting log in to software

Now we upload our step file to this software. After upload process was completed, we have to give some restrictions to model like area which should not buckling. Then we have to select the material to calculate the weight of the chassis.

After all the restrictions and loads are applied to chassis now regenerative process starts. Process will take much time to generate designs according to hardware. After generation was completed we might have many designs which are similar to our design

Now aim to select the design which gave the maximum strength and which satisfy our requirements

Now work is completed for generate the generate the regenerative design now we to save our work as step file same as before, Finalised generated design is given below

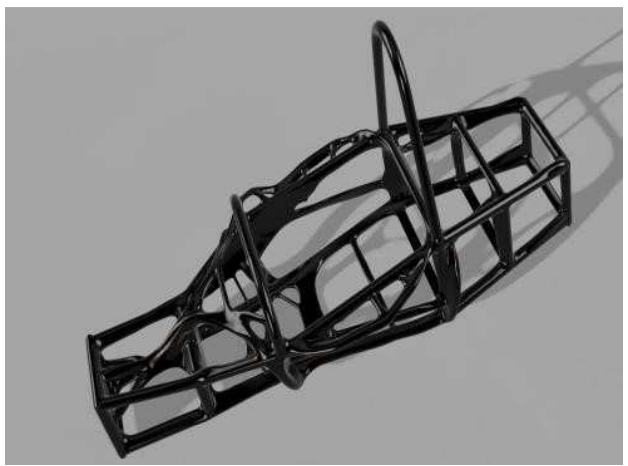

Figure 5: Isometric View of the Generative Design

To manufacture the chassis as per our generative design is very difficult. We can only manufacture that by only 5 axis milling process. To getting that type of process machine is very difficult and to operate that complex machine very skilled labour is needed. For skilled labours high salary, we have to pay. in that case cost of manufacture cost will increase 
and manufacturing time also increase Not only for manufacturing but also for meshing will time also increase due to number of elements are so high so hardware is not supporting to analysis this design

So, we are decided to again design a new model which is similar to our generative design

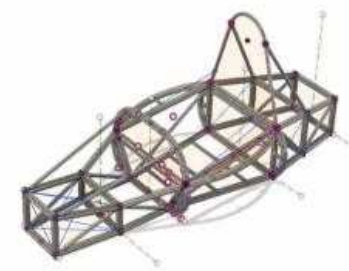

Figure 6: Completed Modified Chassis Design

\section{ANALYSIS}

To make an analysis of my model we used Ansys software version 19.2

Detailed examination of the elements or structure of something typically as a basis for discussion or interpretation is known as Analysis.

The Ansys is a program of the computer for 3D model or design and finite analysis. We can find out how a given design or mechanism are working in given conditions by using the program or software. We can also use this Ansys program to calculating the proper design for given conditions. The analysis is the process of breaking a complex topic or substance into smaller parts in order to gain a better understanding of it.

To get a better knowledge of any system, it should be analyzed based on our requirement and check whether it satisfies our needs.

Based on our need of finding the increase in the strength of the designed chassis, Static Structural Analysis and Crash Analysis have to be performed on it.

\section{Analysis Procedure in Ansys}

Ansys software helps me a lot in some cases which it automatically programmed like default mesh and did analysis for my given model

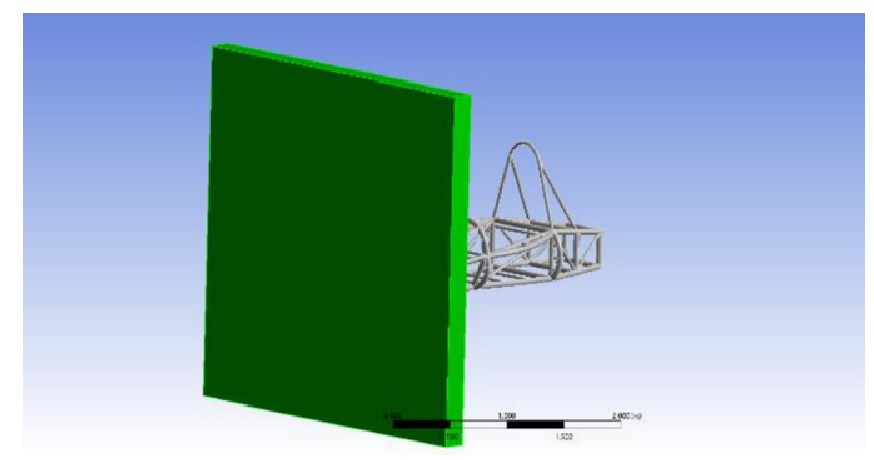

Figure 7: Geometry of the Wall with Chassis 


\section{Materials}

In the analysis, material properties play a major role in many conditions like load, strength, etc. As we discuss before the company won't provide any material details also. so again followed the journal paper.

In that paper, they are designed their design with the structural steel so we are also decided to take the structural as my material

For both space design and generative design are having the same material ie, structural steel

\section{Material Properties}

\section{Physical Properties of the Material Used}

The material chosen for this project is structural steel $\&$ its properties are tabulated below table.

Table 1: Results of Meshing

\begin{tabular}{|l|l|l|}
\hline Statistics & Value & Units \\
\hline Nodes & 18099 & \\
\hline Elements & 72379 & \\
\hline Average Surface Area & 0.11693 & $\mathrm{~m}^{2}$ \\
\hline Minimum Edge Length & $2.7956 \mathrm{e} 006$ & $\mathrm{~m}$ \\
\hline
\end{tabular}

Table 2: Thermal Properties of Structural Steel

\begin{tabular}{|l|c|c|}
\hline \multicolumn{1}{|c|}{ Properties } & Value & Unit \\
\hline Isotropic Secant Coefficient of Thermal Expansion & $12 \mathrm{e}-005$ & $\mathrm{C}^{\wedge} 1$ \\
\hline Specific Heat Constant Pressure & 434 & $\mathrm{~J} \mathrm{~kg}^{\wedge}-1 \mathrm{C}^{\wedge}-1$ \\
\hline Isotropic Thermal Conductivity & 605 & $\mathrm{~W} \mathrm{~m}^{\wedge}-1 \mathrm{C}^{\wedge}-1$ \\
\hline Isotropic Resistivity & $1.7 \mathrm{e}-007$ & $\mathrm{ohmm}$ \\
\hline
\end{tabular}

Table 3: Physical Properties of Structural Steel

\begin{tabular}{|l|c|c|}
\hline \multicolumn{1}{|c|}{ Properties } & Value & Units \\
\hline Density & 7850 & $\mathrm{~kg} \mathrm{~m}^{\wedge}-3$ \\
\hline Elongation (hot rolled) & 16 & $\%$ \\
\hline Yield strength (hot rolled) & 310 & $\mathrm{Mpa}$ \\
\hline Tensile strength (hot rolled) & 565 & $\mathrm{Mpa}$ \\
\hline hardness & 84 & $\mathrm{Rb}$ \\
\hline Tensile Ultimate Strength & $4.6 \mathrm{e}+2$ & $\mathrm{Mpa}$ \\
\hline Tensile Yield Strength & $2.5 \mathrm{e}+2$ & $\mathrm{Mpa}$ \\
\hline
\end{tabular}

\section{Meshing}

Table 4: Quality of Mesh

\begin{tabular}{|l|c|}
\hline & Quality \\
\hline Check Mesh Quality & Yes \\
\hline Target Quality & Default (0.050000) \\
\hline Smoothing & High \\
\hline Mesh Metric & None \\
\hline
\end{tabular}




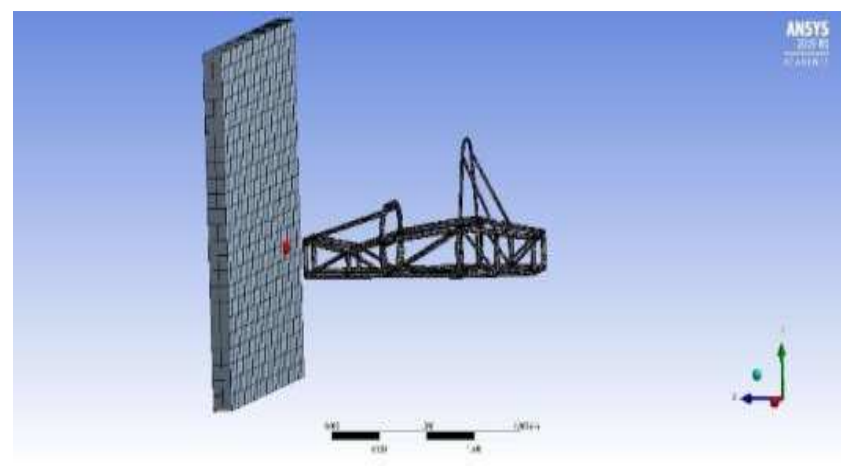

Figure 8: Meshing Isometric View of Wall and Chassis

\section{Explicit Dynamics}

ANSYS Explicit Dynamics is a transient explicit dynamics Workbench application that can perform a variety of engineering simulations, including the modeling of the nonlinear dynamic behavior of solids, fluids, gases, and their interaction.

Table 4: Displacement

\begin{tabular}{|l|l|}
\hline \multicolumn{1}{|c|}{ Define By } & \multicolumn{1}{c|}{ Components } \\
\hline Coordinate System & Global Coordinate System \\
\hline X Component & Free \\
\hline Y Component & $0 . \mathrm{m}$ (ramped) \\
\hline Z Component & Free \\
\hline
\end{tabular}

\section{Solution}

After giving all conditions and programs, solution process will start. Before starting the solution, we have check clearly mesh, initial conditions, mesh quality etc. And we have to select which results want to us. Here we took total deformation and von misses equivalent stress. If all the conditions are okay now our solution part can start

It may take much time to solve to solution. Time to take the solution depends on complex of the shape, number of node and elements, mesh numbers etc.

After solving process was completed, we will get the all the results which already defined in before solving process

\section{Total Deformation}

Deformation is bending in new shape from any predefined shape of body. If we consider whole body deformation at a time is called the total deformation. Deformation is always in $\mathrm{mm}$. If we got less deformation in results then our design has felt less stress which mean good design.

All results values are tabulated below

Table 5: Total Deformation in Static Analysis

\begin{tabular}{|c|c|c|}
\hline Space Model & Modified Model & Units \\
\hline failed & 1.45 & $\mathrm{~mm}$ \\
\hline
\end{tabular}




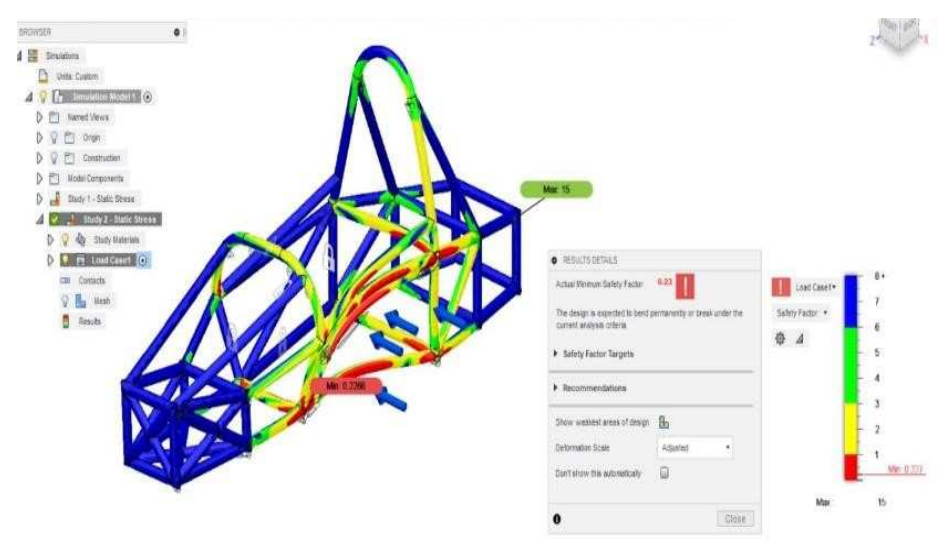

Figure 9: Total Deformation of Space Model in Static Analysis

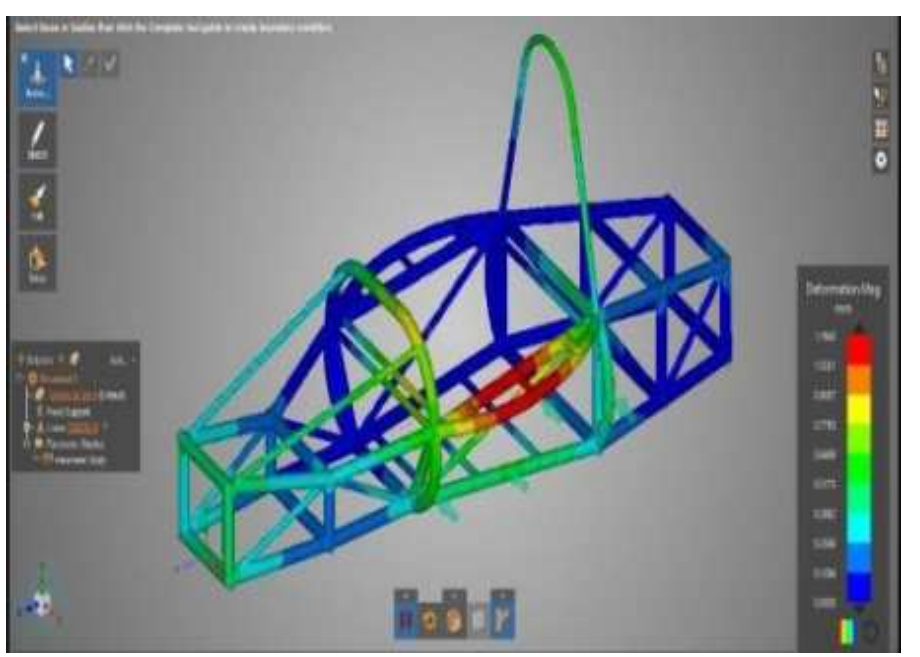

Figure 10: Total Deformation of Modified Model in Static Analysis (1.1645mm)

Table 6: Results of Total Deformation in Dynamics Analysis

\begin{tabular}{|l|l|l|}
\hline & Value & Units \\
\hline Minimum & 0. & $\mathrm{~m}$ \\
\hline Maximum & 0.39123 & $\mathrm{~m}$ \\
\hline Average & 0.28351 & $\mathrm{~m}$ \\
\hline Minimum Occurs On & Solid & \\
\hline Maximum Occurs On & Race Model & \\
\hline
\end{tabular}

Table 7: Information of Total Deformation in Dynamics Analysis

\begin{tabular}{|l|l|l|}
\hline \multicolumn{3}{|c|}{ Information } \\
\hline Property & Value & Units \\
\hline Time & $2.5 \mathrm{e}-002$ & $\mathrm{~s}$ \\
\hline Set & 21 & \\
\hline Cycle Number & 161482 & \\
\hline
\end{tabular}




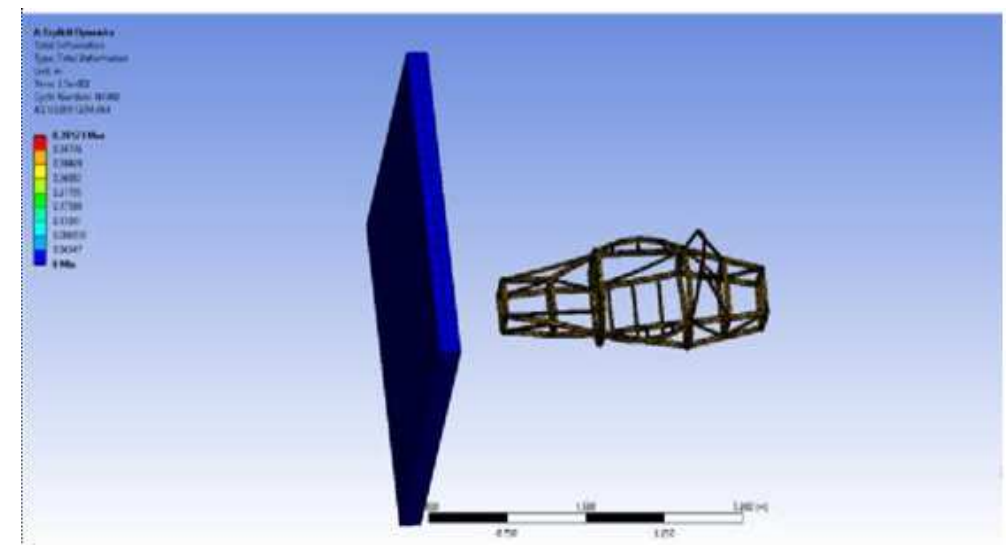

Graph 1: Total Deformation with Respect Time in Dynamics Analysis

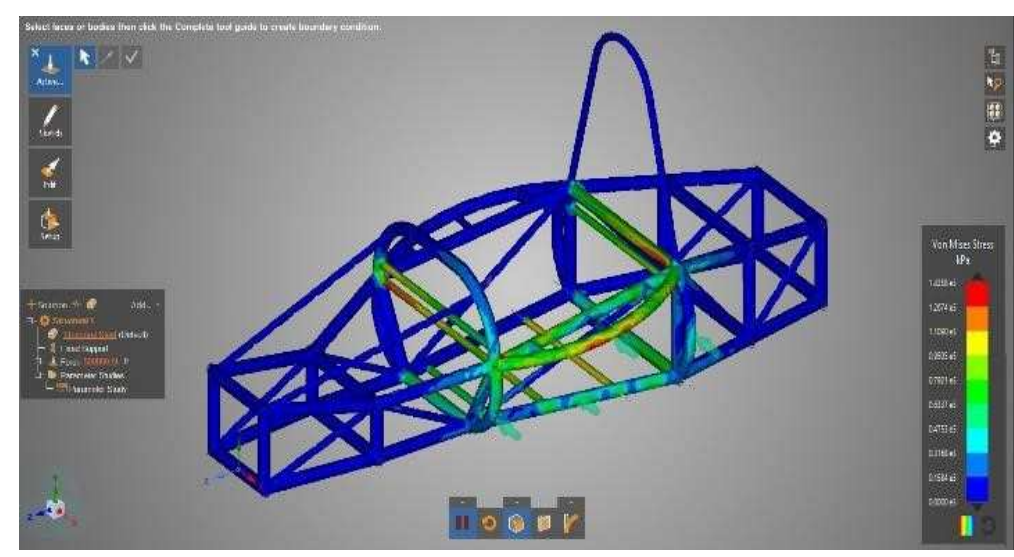

Figure 11: Total Deformation in Dynamics Analysis (0.39121mm)

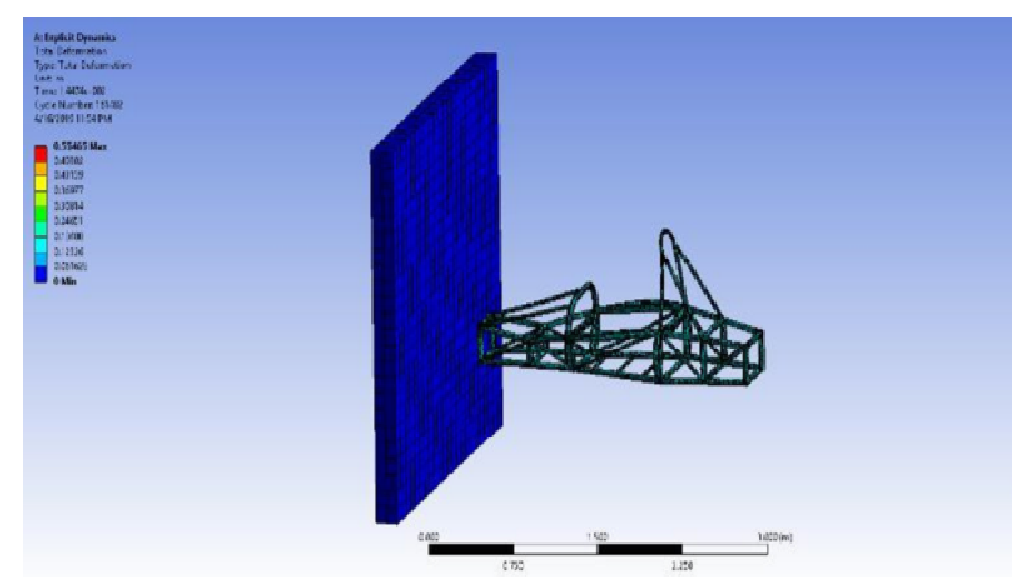

Figure 12: Total Deformation in Dynamics Analysis (0.55855mm) 5.2.6.3.2 von Mises Stress All the values are all tabulated below

Table 8: Equivalent stress in Static Analysis

\begin{tabular}{|c|c|c|c|}
\hline Material & Space Model & Modified Model & Units \\
\hline 310 & 759 & 142 & $\mathrm{mpa}$ \\
\hline
\end{tabular}



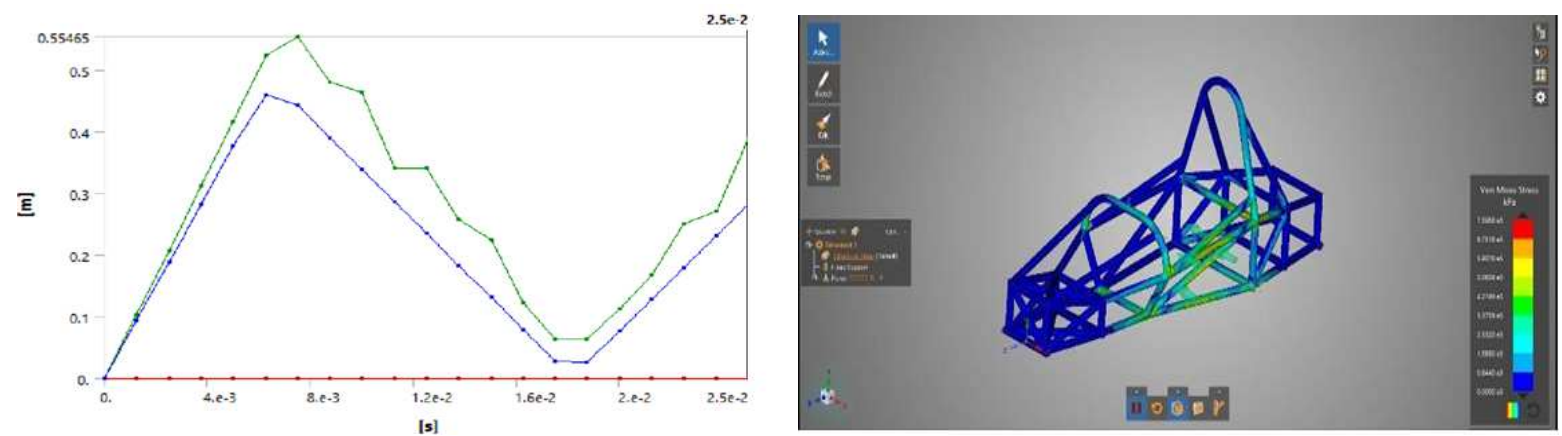

Figure 13: Equivalent Stress in Static Analysis of Space Model (7.5958e5 Kpa)

Table 9

\begin{tabular}{|c|c|c|}
\hline \multicolumn{3}{|c|}{ Equivalent (Von-Mises) Stress } \\
\hline Property & Value & units \\
\hline Type & Total Deformation & \\
\hline By & Time & $\mathrm{sec}$ \\
\hline Display Time & Last & $\mathrm{sec}$ \\
\hline Calculate Time History & Yes & \\
\hline Suppressed & No & \\
\hline
\end{tabular}

Table 10: Results of Equivalent (Von-Mises) Stress

\begin{tabular}{|c|c|c|}
\hline Properties & Value & Units \\
\hline Minimum & $7.089 \mathrm{e}+005$ & $\mathrm{pa}$ \\
\hline Maximum & $6.155 \mathrm{e}+009$ & $\mathrm{pa}$ \\
\hline Average & $9.011 \mathrm{e}+008$ & $\mathrm{pa}$ \\
\hline Minimum Occurs On & Solid & \\
\hline
\end{tabular}

Table 11: Information of Equivalent (von-Mises) Stress

\begin{tabular}{|l|c|c|}
\hline \multicolumn{3}{|c|}{ Information } \\
\hline \multicolumn{1}{|c|}{ Property } & Value & Units \\
\hline Time & $2.5 \mathrm{e}-002$ & $\mathrm{~s}$ \\
\hline Set & 21 & \\
\hline Cycle Number & 161482 & \\
\hline
\end{tabular}

As we discuss before in the modeling, we are design this chassis for side impact also, mostly all designs are design by considering the front impact of chassis. Front impact is happening when the car is in the race some time unexpectedly accidents will occur. Then car will be going to hit the wall or other car. At time of hitting to wall only chassis will help to save the driver from buckling. So that's why we design this chassis which is more strength. But in some cases, while we are in goods way also some other vehicle come and hit our car in side of car or we by skidding our car we will go hit wall also. In this cases chassis will got into failure. Driver will be in bucking condition

To avoid those conditions, we design this chassis. To prove this chassis is good we did not only static analyses but also crash analysis

That analysis is as same as did before front crash analysis. Here also he did the same we are going to hit same chassis to wall with the specific velocity with in specific time but in side of chassis

Already we saw the step by step procedure of crash analysis before so now are going see briefly about side crash analysis 


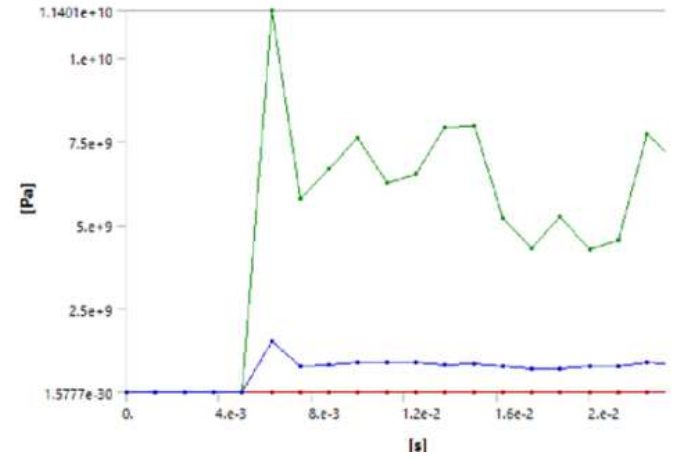

Graph 5: Stress vs Time

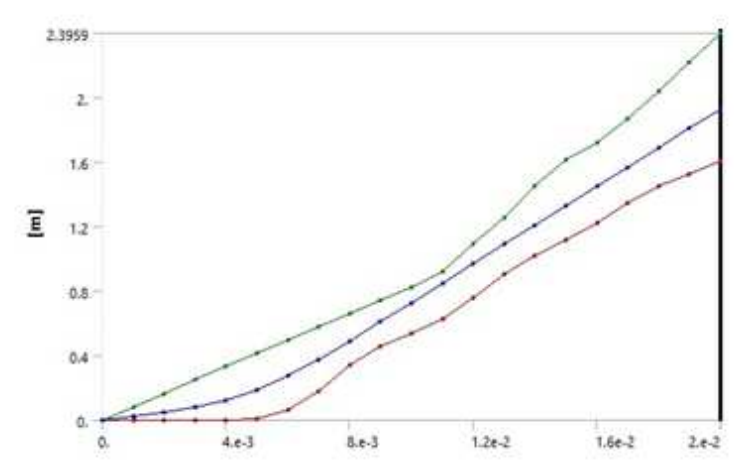

Graph 6: Total Deformation of Side Crash Analysis

Total Deformation of Side Crash Analysis
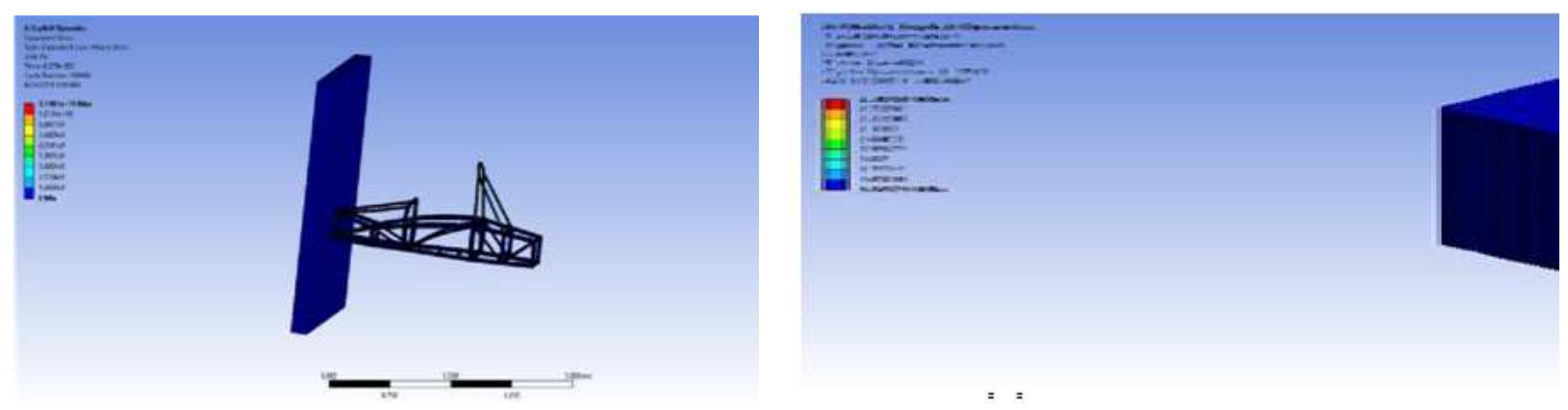

Figure 14: Total Deformation of Side Crash Analysis (2.3959m) Equivalent Stress

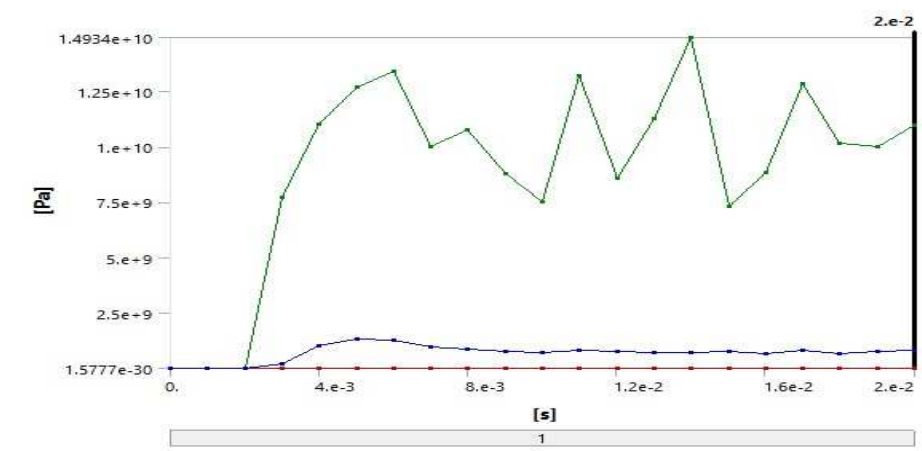

Graph 7: Equivalent Stress

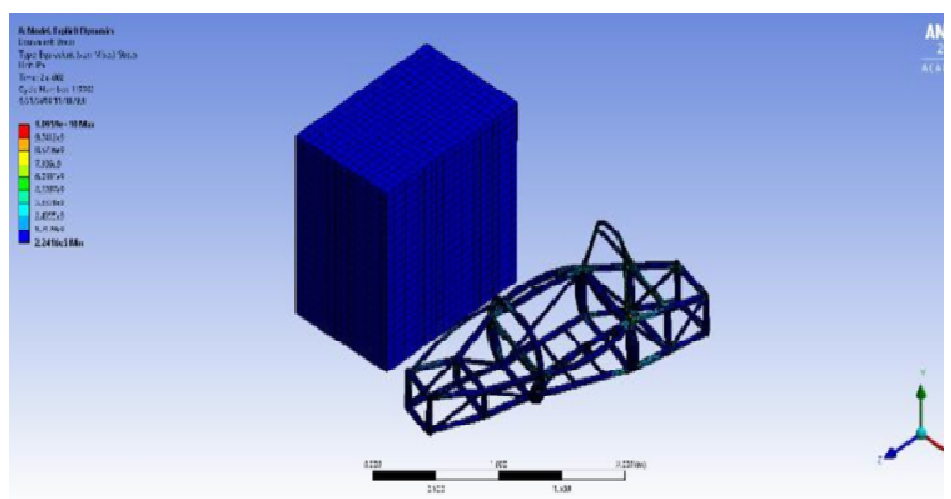

Figure 15: Equivalent Stress (1.0959e10pa) 


\section{CONCLUSIONS}

After did all this analysis for both front and side crash analysis we are concluded that my design will gives best results by hitting the chassis to wall when compare to we static analysis of space model.

When we compare with space model stress. My design has the less stress than the space model by having the less stress of my design we can conclude that my design has more strength than space design

\section{REFERENCES}

1. Alperen Kale, Design of Formula Student Race Car Chassis

2. Arindam Ghosh, Structural Analysis Of Student Formula Race Car Chassis, Assistant Professor, Dept. Of Mechanical Engineering, University Of Engineering \& Management, West Bengal, India

3. Arjun Singh, Design And Simulation Of F-1 Car Chassis, Dept. Mechanical Engineering, Rajkiya Engineering College, Banda, India

4. Chandan S N, Design, Analysis And Optimization Of Race Car Chassis For Its Structural Performance Assistant Professor, Department Of Mechanical Engineering, Nittemeenakshi Institute Of Technology,

5. S. Palanisamy, Design And Fabrication Of F1 Race Car Chassis Frame, Dept. Of Mechanical Engg, Muthayammal Engineering College Rasipuram

6. Anand, D, Gupta, A, \& Subramanian, J. Validation Of Torsional Rigidity Of Fsae Chassis.

7. Vinayakanagarajaiah, Design, Car Chassis For Its Structural Performance, Assistant Professor, Department Of Mechanical Engineering, Nittemeenakshi Institute Of Technology, Bangalore-64, India. Abstract

8. J Rajesh, Metla Suresh, Vehicle Crash Analysis Of Race Car Using Ls-Dyna, Department Of Mechanical Engineering Chirala Engineering College, Chirala

9. Meenakshi C. M, Kumar A, Priyadarshi A, Dash D. K, Krishna H, Analysis Of Spur Gear Using Finite Element Analysis, Middle - East Journal Of Scientific Research, V-12, I-12, Pp-1672-1674, Y-2012

10. Rubanprakash, Rakesh, Aravindan, Jothimurugan, Meenakshi C. M, Design And Fabrication Of Hydro Power Generation System From Waste Water, International Journal Of Mechanical Engineering And Technology, V-8, I-8, Pp-1606-1609, Y2017

11. Davlechina, A. P, \& Mendoza, J. L. Methodology Of Vehicle Operational Loads Assessment During Vehicle Development Process For Further Chassis And Body-In-White Strength And Durability Analysis.

12. C. M. Meenakshi Dr. A. Krishnamoorthy The Mechanical Characterization Of Mono And Hybrid Fiber Reinforced Composites Using Experimental And Finite Element Analysis Methods, International Journal Of Mechanical And Production Engineering Research And Development (Ijmperd) Issn (P): 2249-6890; Issn (E): 2249-8001, Vol. 9, Issue 3, Jun 2019, 189 196.

13. C. M. Meenakshi Dr. A. Krishnamoorthy hygrothermal Analysis And Comparison Of Glass Fiber And Hybrid Fiber Reinforced Polyester Composites, Asian Journal Of Chemistry, Vol.31 No 3 Pg-687-689,2019,

https://doi.org/10.14233/ajchem.2019.21790 
